Original article

\title{
INCIDENCE OF DIFFERENT TYPES OF DYSTOCIA IN DIFFERENT SEASONS OF THE YEAR AND PARITIES IN IRANIAN HOLSTEIN DAIRY COWS
}

\author{
M. GOLI \\ Department of Clinical Science, Faculty of Veterinary Medicine, \\ Razi University, Kermanshah, Iran
}

\section{Summary}

Goli, M., 2018. Incidence of different types of dystocia in different seasons of the year and parities in Iranian Holstein dairy cows. Bulg. J. Vet. Med., 21, No 3, 336-346.

Dystocia (DYS) is an important problem in Holstein cattle and imposes important economic losses on cattle producers. The etiologies and types of DYS are various and different factors can influence its incidence. In the present study, incidence of different types of dystocia was investigated in different seasons and parities in Holstein cows. One hundred and eighty two primi- and multiparous cows with DYS were included in the study. The results showed significantly more calf births in anterior presentation to first-calf heifers compared to those born to cows in parities $2-3$ or $\geq 4(\mathrm{P} \leq 0.05)$. There was no significant difference in the number of calves born in anterior presentation between cows in parities $2-3$ and those in parities $\geq 4(\mathrm{P}>0.05)$. Also, significantly more dystocia cases were encountered in first-calf heifers compared with those in cows in parities $2-3$ or $\geq 4(\mathrm{P} \leq 0.05)$ but there was no significant difference in this regard between the cows in parities $2-3$ and those in parities $\geq 4(P>0.05)$. In addition, the results revealed that DYS due to foetopelvic disproportion (FPD) mostly affected the primiparous cows and that the multiparous cows were mostly affected by dystocia due to twin birth (TB), uterine inertia (UI) and uterine torsion (UT). Moreover, the results showed that significantly most DYS cases occurred during winter compared with spring, summer or autumn $(\mathrm{P} \leq 0.05)$, of which the majority was due to FPD. On the other hand, the least DYS cases were observed in summer months, of which the majority was again due to FPD. Finally, there was no significant difference in the overall incidence of dystocia between spring, summer and autumn $(\mathrm{P}>0.05)$.

Key words: dystocia, Holstein cows, parity, season

\section{INTRODUCTION}

Calving difficulty or dystocia (DYS) is an important problem in Holstein cattle; about one birth of every 5 to first-parity dams "need assistance" (Meyer et al., 2001). DYS has been defined as a difficult birth resulting in prolonged calving or severe assisted extraction of the calf at birth but assisted calving has been defined as a birth in which assistance is required (e.g., correction of malposition), but this 
may not necessarily result in DYS (Mee, 2004). According to Sasaki et al. (2014), DYS is a calving that requires veterinary assistance. Others have defined DYS as births that were reported as requiring considerable force or extremely difficult for calving difficulty score rated on a 1 to 5 scale (Norman et al., 2010).

DYS can result from the failure of expulsive forces during parturition, birth canal inadequacy, foetal malposition, disproportionate calf size to the dam's pelvic size (Noakes et al., 2009), twins, and uterine torsion (Mee, 2008). Abnormally short or long gestation length, and overfeeding or underfeeding in the last trimester can increase the risk of DYS (Proudfoot et al., 2009). In primiparous cows, an important or actually the most important factor is the relationship between the calf size and the size of the birth canal (Lombard et al., 2007; Mee, 2008; Mee et al., 2011; Schuenemann et al., 2011). Calf birth weight has been identified as one of the most significant risk factors for the occurrence of DYS in heifers and pluriparous females (Micke et al., 2010). Vulval stenoses have also been mentioned to be one of the most frequent causes of DYS in primiparous dams (Mee, 2008), whereas foetal malpresentation or maternal-related causes (e.g. uterine torsion, hypocalcaemia, cervical stenosis) are the most frequent causes of DYS in multiparous dairy cows (Lombard et al., 2007; Mee, 2008). DYS rate can be up to three times greater in primiparae compared to that in pluriparae (Meyer et al., 2001). Weak labour can be the cause as well as a consequence of a difficult calving. Primary weak labour is reported to be most frequent in older cows, possibly often associated with milk fever (Meijering, 1984) or hypocalcaemia (Schuenemann et al., 2011). Insufficient dilatation of the cervix and uterine torsion may contribute significantly to the incidence of severe DYS, especially in older cows (Meijering, 1984). The increase in calving assistance and DYS at twin calvings has been attributed to abnormal presentation, increased number of dead calves, the total weight of calves born and uterine inertia (Lombard et al., 2007).

It has been shown that parity is a large contributor to calving difficulty although effects of parity were probably due to physical maturation, including increased pelvic dimensions (Nix et al., 1998). These authors reported that birth weight and parity of dam had the greatest influence on DYS. Cold weather during the last trimester has been associated with increased dry matter intake, increased thyroid hormone concentration, increased blood and nutrient flow to the uterus, increased gestation length and reduced plasma oestradiol concentrations leading to increased birthweight and DYS (Mee, 2008).

The month of calving is also shown to influence DYS frequency. High incidence of DYS was found in autumn and winter with peaks in December and a decrease from February to May (Osinga, 1978).

To the author's knowledge there is no study on the incidence of different types of DYS in different parities of dams and seasons of the year and the relationship between them in Iranian Holstein cows. So, these parameters were investigated in the present study.

\section{MATERIALS AND METHODS}

\section{Animals and location}

The study was conducted in Urmia (altitude $1,332 \mathrm{~m}$ above sea level; $37^{\circ} 33^{\prime} 19^{\prime \prime} \mathrm{N}, 45^{\circ} 04^{\prime} 21^{\prime \prime} \mathrm{E}$; with cold winters, mild springs, hot dry summers and cool autumns; coldest $-2.6{ }^{\circ} \mathrm{C}$ and hottest $-31.2{ }^{\circ} \mathrm{C}$ average temperature in June and 
July, respectively), the capital city in West Azarbayejan province, Iran. A total of 182 primi- and multiparous Iranian Holstein cows that could not deliver their foetuses at least two hours after the beginning of the second stage of the labour at their natural spontaneous calving events were considered as suffering from DYS and included in the study. All dystocic cows were examined and treated personally. The cows were non-seasonal, year-round calvers, kept in confinement, fed a mixture of food consisting of alfalfa hay, chopped straw, grass and commercial concentrate and milked twice daily. Parity ranged from 1 to 9. All cows had been artificially inseminated with frozen-thawed semen of proven sires by AI technicians after being detected in standing estrus.

Data collection

Data including causative factors for dystocia - deviation of foetal head (DFH), foetal limb malposture (FLM), foetal malposition (FMP), foetopelvic disproportion (FPD), foetal malpresentation (MPR), twin birth (TB), uterine inertia (UI), uterine torsion (UT), parity of the dams (1, $2-3, \geq 4)$ and calving season were recorded for final assessment.

\section{Statistical analysis}

Pearson Chi-Square test (SPSS, Version 23, Chicago, IL, USA) was used to evaluate the differences in the incidences of DYS types in different parities of the dams; DYS types in different seasons of the year; and anterior or posterior presentation in different parities of the dams suffering from DYS. Statistical level of significance was set at $\mathrm{P} \leq 0.05$.

\section{RESULTS}

The number and percentage of anterior and posterior presentation of calves born

Table 1. Relationship between dam parity and calf presentation in Holstein cows suffered from dystocia $(\mathrm{n}=182)$

\begin{tabular}{|c|c|c|c|c|}
\hline & \multicolumn{4}{|c|}{ Dam parity } \\
\hline & 1 & $2-3$ & $\geq 4$ & Total \\
\hline \multicolumn{5}{|c|}{ Anterior calf presentation } \\
\hline count & 95 & 30 & 37 & 162 \\
\hline$\%$ within presentation & 58.6 & 18.5 & 22.8 & 100.0 \\
\hline$\%$ within parity & $94.1^{\mathrm{a}}$ & $85.7^{\mathrm{a}, \mathrm{b}}$ & $80.4^{b}$ & 89.0 \\
\hline$\%$ of total & 52.2 & 16.5 & 20.3 & $89.0^{\mathrm{a}}$ \\
\hline \multicolumn{5}{|c|}{ Posterior calf presentation } \\
\hline count & 6 & 5 & 9 & 20 \\
\hline$\%$ within presentation & 30.0 & 25.0 & 45.0 & 100.0 \\
\hline$\%$ within parity & 5.9 & 14.3 & 19.6 & 11.0 \\
\hline$\%$ of total & 3.3 & 2.7 & 4.9 & $11.0^{\mathrm{b}}$ \\
\hline \multicolumn{5}{|l|}{ Total } \\
\hline count & 101 & 35 & 46 & 182 \\
\hline$\%$ within presentation & 55.5 & 19.2 & 25.3 & 100.0 \\
\hline$\%$ within parity & 100.0 & 100.0 & 100.0 & 100.0 \\
\hline$\%$ of total & 55.5 & 19.2 & 25.3 & 100.0 \\
\hline
\end{tabular}

\footnotetext{
${ }^{\mathrm{a}, \mathrm{b}}$ Different superscript letters within a row or column denote significant difference.
} 
to Holstein cows with different parities that suffered from DYS is presented in Table 1. The results of the statistical analysis demonstrated a significant difference in the incidence of anterior or posterior presentation in calves born to primiparous cows compared to those born to cows with parity $\geq 4(\mathrm{P}<0.05)$. In other words, more calves were born in anterior presentation to first-calf heifers in comparison to those born in anterior presentation to cows with parity $\geq 4$ (Table 1 ). However, there were no significant differences in the number and percentage between calves born in anterior or posterior presentation to cows with parity 1 and 2-3 or between those born in anterior or posterior presentation to cows with parity $2-3$ and $\geq 4(\mathrm{P} \geq 0.05)$.

Table 2 presents the distribution of different types of DYS in Holstein cows with different parities. The most frequent type of DYS observed was that due to FPD. On the other hand, the least frequent type of DYS encountered was that caused by MPR with only one case. The other observed types of DYS in descending order were DFH, FLM or UI, TB, FMP and UT (Table 2). In addition, the results of the present study revealed that DYS due to FPD most often affected the primiparous Holstein dairy cows $(n=62,79.5 \%)$ and that the multiparous cows were much less affected by FPD compared to the first-calf heifers. Also, the results demonstrated that half of the cows affected by DYS due to UI were among the cows with parity $\geq 4$. Moreover, the results showed that the majority of twin births took place among cows with parity $\geq 4(85.7 \%)$.

Table 3 presents the seasonal distribution of different types of DYS in Holstein dairy cows. As shown, most DYS cases occurred in winter months in comparison to other seasons, of which the majority was due to FPD ( $n=27,15.3 \%)$. The incidence of difficult births in autumn months was lower than that occurringd in winter months but higher than that seen in spring or summer months. On the other hand, the least DYS cases were observed in summer months $(17.6 \%)$, of which the majority was due to FPD (Table 3).

\section{DISCUSSION}

It has been suggested that normal presentation may be defined as anterior presentation, dorsal position, and the foetal head resting on fully extended forelegs and that any presentation, position, or posture deviating from this description was classified as a malpresentation (Holland et al., 1993). However, malpresentation including posterior dorsal presentation with extended hind limbs at birth has generally not been considered to be a significant factor contributing to DYS. Most researchers have considered malpresentation to be negligible and random in nature and, as such, have often omitted these births from analysis (Nix et al., 1998). So, in the present study, posterior presentation was considered normal and not included in the study unless there was a situation such as a mismatch between the calf size and the dam's pelvic area, retention of a hind limb, a breech presentation, a malposition, and so on, in which giving assistance in order to deliver the calf was unavoidable. Overall, among the calves needing assistance for delivery $11 \%$ (20 calves) were born in posterior presentation, the majority of which were born to cows in parities $\geq 4$. In the current study, only one ventrotransverse presentation $(0.6 \%$ of total births) was encountered, which is regarded to be rare in cattle and may be the 
Incidence of different types of dystocia in different seasons of the year and parities in Iranian ....

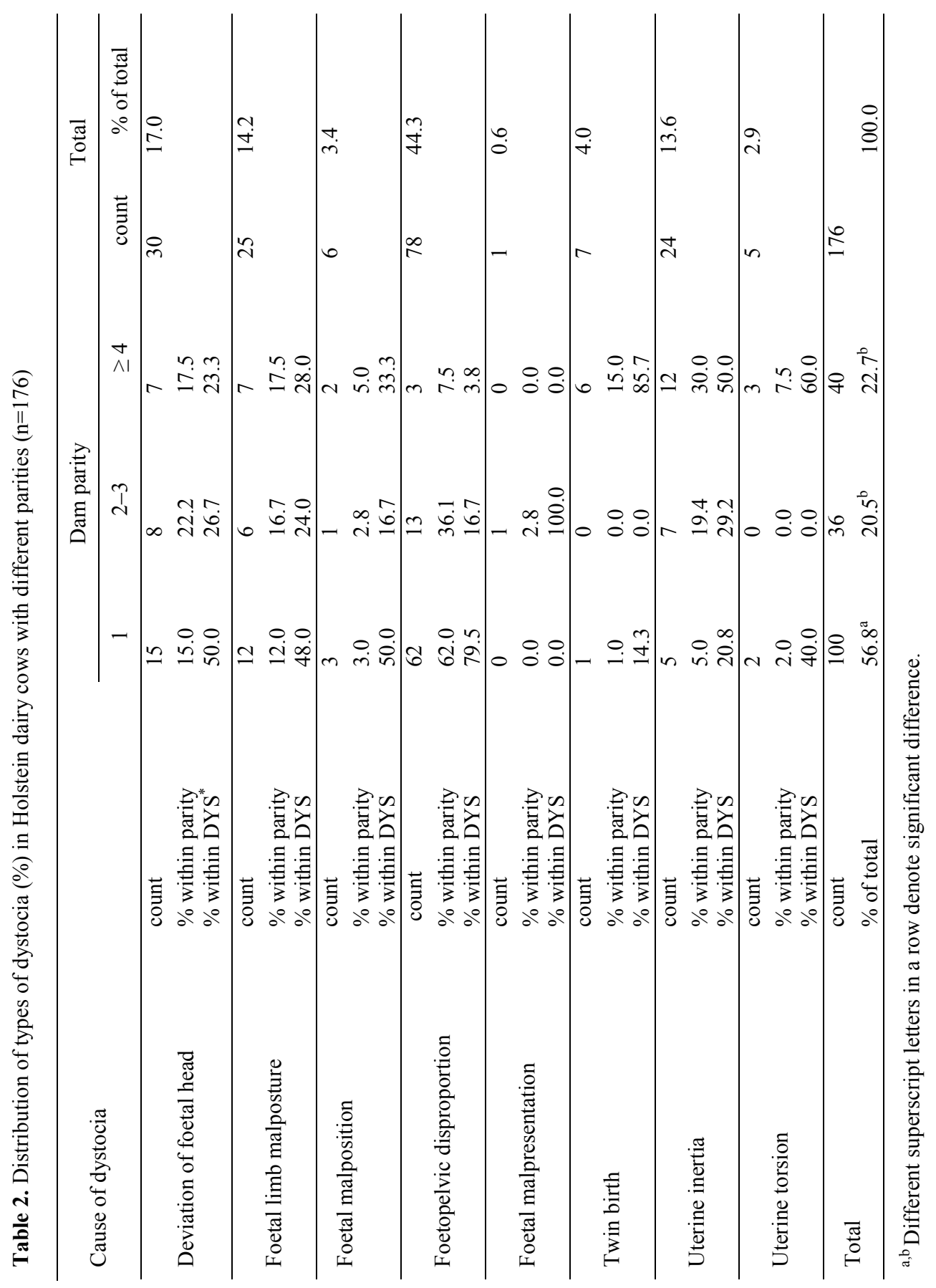




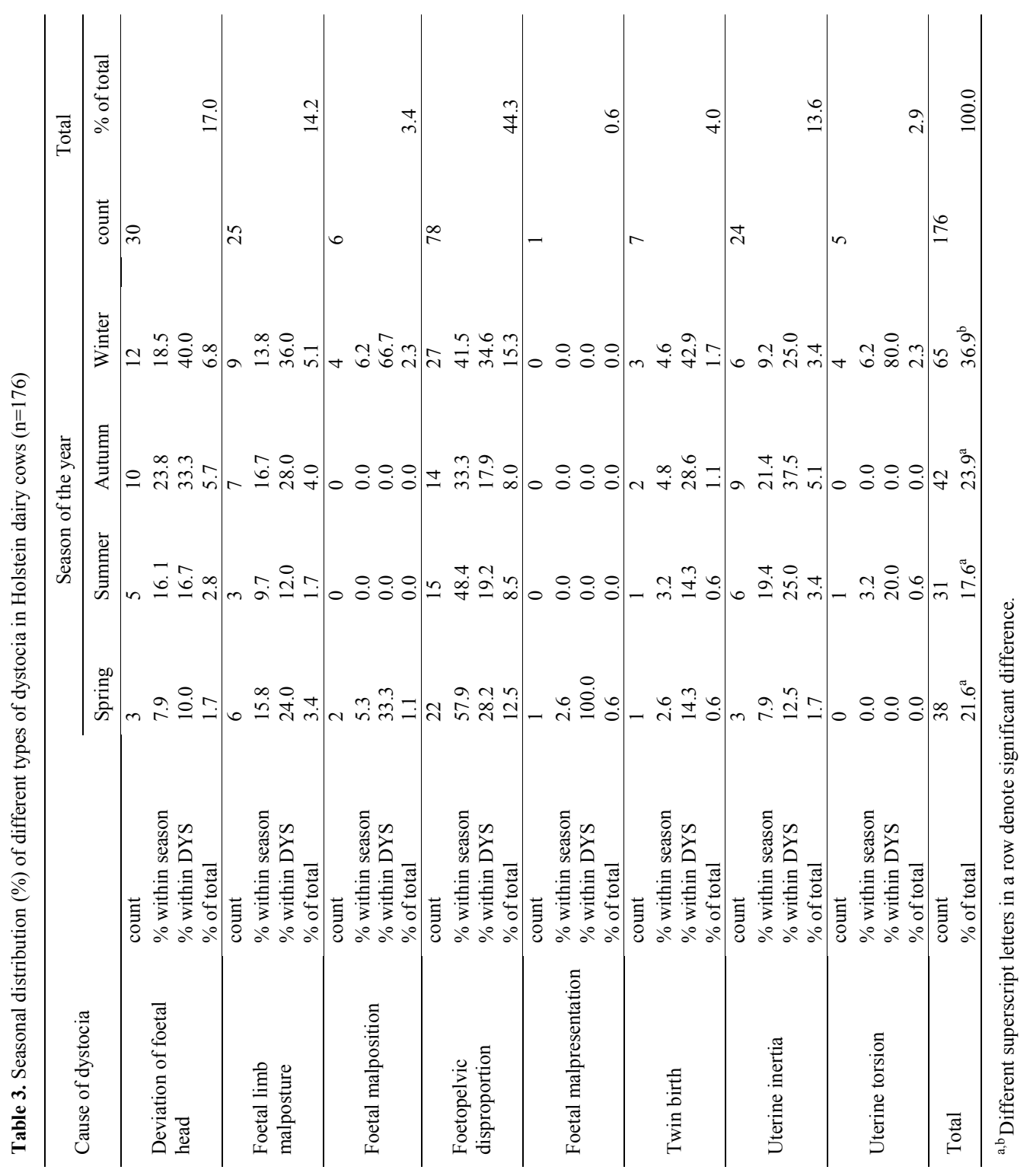


result of impaired maternal myometrial function. Improper foetal alignment with the birth canal during parturition, or malpresentation certainly contributes to the incidence of DYS, yet it is encountered rather infrequently (Holland et al., 1993). Holland et al. (1993) also reported two transverse presentations $(1.3 \%)$ and one oblique ventrovertical presentation $(0.6 \%)$ which was not encountered in the current study. The findings of the present study are also in agreement with the results of another study which support the common beliefs that malpresentations at birth are negligible in relation to the total numbers of calves experiencing DYS (Nix et al., 1998). In their study, twenty calves displayed malpresentation including posterior presentation at birth, accounting for less than $1 \%$ of total births. According to these authors, posterior presentation represented $70 \%$ of malpresentations (Nix et al., 1998). In the study by Holland et al. (1993), malpresentation including posterior presentation was reported as $4 \%$ of total births. The authors observed $72.8 \%$ incidence of posterior presentation (Holland et al., 1993). Meijering (1984) reported in a review article that posterior presentation of the calf was responsible for $20-40 \%$ of the DYS cases recorded by inquiry or met in veterinary practice. The fact that this cause of DYS is relatively more frequently observed in older cows than in heifers may be attributable to the higher rate of FPD in the latter group (Meijering, 1984). Majeed et al. (1989) reported that calves in the anterior presentation causing DYS formed approximately $51.7 \%$ of the cases, while posterior presentations formed $16.3 \%$. In the current study, regardless of the single calf presented in the ventrotransverse presentation, all other non-anterior presentation births took place in posterior presentation.
This discrepancy between the current study and those mentioned above might have been due to the great difference in the number of births evaluated.

By far the most common type of DYS in domesticated dairy cattle is FPD and this is the primary reason why veterinarians perform caesarean operations in these cattle. The two primary determinants of FPD are, in order of importance, calf birthweight and maternal pelvic size which account for $50 \%$ and $5-10 \%$ of the phenotypic variance in DYS, respectively (Mee, 2008). Mee (2008) also reported that in primiparous cows, an important factor is the relationship between the calf size and the size of the birth canal. Some researchers reported that more than 50\% of obstetrical cases were due to FPD (Meijering, 1984; Berger et al., 1992). Also, others reported that of the factors contributing to DYS, calf birth weight and dam pelvic area are the most influential. As a result, most calving difficulties are due to relatively oversized calves (Holland et al., 1993; Nix et al., 1998) especially in first-calf heifers (Meijering, 1984). Holland et al. (1993) reported that most of the assisted births $(56.0 \%)$ occurred among first-calf, 2-year-old heifers. In the current study, in agreement with others, the most important single cause of DYS was FPD (44.3\%), of which the majority $(79.5 \%)$ occurred among heifers and the minority took place among the cows with parities $\geq 4$ (Table 2 ). Also, the results showed that in all seasons, the main single cause of DYS was FPD (Table 3 ).

The second important single cause of DYS observed in the current study was DFH, which most commonly occurred among first-calf heifers and during winter. In other words, the lowest frequency of this type of dystocia occurred among the cows with parities $\geq 4$ and during the 
months of spring (Tables 1 and 2). In the present study, flexion of the joints of foetal fore or hind limbs presented in anterior or posterior presentation, respectively, was considered as FLM. It was the third important cause of DYS observed in this study and among first-calf heifers and during winter months (Tables 1 and 2). In the studies by Holland et al. (1993) and Nix et al. (1998), FLM was the second most frequent cause of DYS observed. They observed higher incidences of FLM (21.5\% and $20 \%$, respectively) and lower incidences of DFH $(2.5 \%$ and $10 \%$, respectively) (Holland et al., 1993; Nix et al., 1998) in comparison with those in the current study. There is no explanation to justify the discrepancy between the findings of the present study and those of Holland et al. (1993) and Nix et al. (1998) except the differences in the number of the cows evaluated in these studies. UI, TB, FMP and UT were the subsequent important causes of DYS encountered in the present study, respectively. Most UIs and TBs were seen among the cows with parities $\geq 4$ and during the colder months of the year, i.e. autumn and winter. Only one TB occurred in a first-calf heifer (Tables 1 and 2). This finding is in agreement with other studies in which it was reported that in multiparous cows, DYS is often related to twins or malposition of the calf (Mee, 2008). Moreover, the increase in calving assistance and DYS at twin calvings has been attributed to abnormal presentation, increased number of dead calves, the total weight of calves born and uterine inertia (Mee et al., 2011). In addition, Lombard et al. (2007) reported that more than $10 \%$ of calves in their study were twins with the majority of twins born to multiparous cows. It was also reported that maternal-related causes (e.g., uterine torsion, hypocalcaemia and cervical steno- sis) are the most frequent causes of DYS in multiparous dairy cows (Meijering, 1984; Schuenemann et al., 2011). It has been reported that UI, in which the cervix is fully dilated but myometrial contractions are too weak to expel the foetus, is associated with approximately $10 \%$ of all dairy cattle DYS, primarily in pluriparae (Mee, 2008). In another study, it has been reported that UI formed $6 \%$ of DYS cases and that this might be due to nutritional deficiency causing hypocalcaemia without paresis leading to the absence of myometrial contractions (Majeed et al., 1989). In the current study, higher incidence of dystocia due to UI was encountered $(13.6 \%)$, the majority $(79.2 \%)$ of which occurred among multiparous cows. The discrepancy between the findings of the present study and those of others might be due to the nutrition status and/or the breed of the cows evaluated. It has been reported that insufficient dilatation of the cervix and UT may contribute significantly to the incidence of severe DYS, especially in older cows and that the relative contribution of these causes is probably low in data collected by inquiry (Meijering, 1984), which confirms the finding of the present study in which only five DYS cases $(2.9 \%)$ were observed, three of them among multiparous cows.

Parity of dam has also been shown to be a large contributor to calving difficulty, although effects of parity were probably due to physical maturation, including increased pelvic dimensions (Nix et al., 1998). It has been reported that multiparous dams experienced significantly less DYS than primiparous dams (Nix et al., 1998). Also it has been shown that there was a greater likelihood of DYS in firstparity dairy cows (Meijering, 1984; Dematawewa \& Berger, 1997; Steinbock et al., 2003; Berry et al., 2007; Norman et 
al., 2010; Mee et al., 2011; Ghanem et al., 2013). The increased risk of DYS in primiparae has been attributed to foetomaternal disproportion, immaturity and incomplete development in young heifers and over fatness and uterine inertia in older heifers (Mee et al., 2011). Olson et al. (2009) reported that the calf from a primiparous cow was 2.50 times more likely to be born with assistance than if born from a multiparous cow. Meyer et al. (2001) reported $>28 \%$ DYS in first-parity births in US Holsteins. The results of the present study showed that overall $56.8 \%$ of assisted calvings occurred in firstcalving heifers. The reasons for the occurrence of more DYS among the first-calf heifers in the current study in comparison to other reports are probably the differences in the pelvic sizes of the dams and/or the birthweights of the calves born to the first calf-heifers. The body sizes of the Holstein heifers used in the current study resp. their pelvic areas were probably smaller than those of the Holstein heifers used in other studies.

It has been shown that season of the year influenced the incidence of DYS in cattle (Majeed et al., 1989; Manfredi et al., 1991; Lombard et al., 2007; Mee et al. 2011; Ghanem et al., 2013). Seasonal differences in DYS risk have been attributed to increased gestation length, calf birth weight and stillbirth in colder weather (Mee et al., 2011). It has been reported that high a incidence of DYS was found in autumn and winter. The high rate of DYS in autumn and winter with a peak in December coincided with high birth weights. In spring the decreasing DYS rate is accompanied by a decrease in birth weight (Osinga, 1978). In the present study most of the DYS events occurred during autumn and winter months compared to those occurred during spring and summer months, which is in agreement with those reported by other studies (Osinga, 1978; Majeed et al., 1989; Manfredi et al., 1991; Nix et al., 1998). Nix et al. (1998) suggested that since nearly half of every gestation period consistently occurred during periods of high ambient temperature and humidity, it appears logical that lowered birthweight due to chronic heat could have contributed to the observed low levels of DYS. Manfredi et al. (1991) reported higher DYS incidence during the winter and concluded that more difficult births are expected during winter months, when the dams are first-calvers, or when the calf is a male. Majeed et al. (1989) reported a higher risk of DYS during the winter and autumn as compared with spring or summer. The higher risk of DYS in the winter can be explained by the fact that more calvings occur during this season (Majeed et al., 1989), which is in agreement with the present study in which most calvings occurred during winter. Osinga (1978) reported that in spring the decreasing DYS rate was accompanied by a decrease in birth weight. In the current study calves' weights were not recorded but in agreement with Osinga (1978) less DYS cases were encountered in spring compared to those observed in winter which is probably due to less calf birthweight in spring than that in winter. However, Mee et al. (2011) reported a greater likelihood of calving assistance and of DYS in spring and autumn, which is in disagreement with the results of the present study in which DYS during spring or autumn was found less probable compared to that in winter. Also, numerically more DYS cases were recorded in the summer, perhaps because of thermal stress (Ghanem et al., 2013), which is in disagreement with the results of the present study and many others. In the present study, the 
least DYS events occurred in summer in comparison to other seasons.

\section{CONCLUSIONS}

The results of the present study showed significantly more calf births in anterior presentation to first-calf heifers compared to those born to cows in parities $2-3$ or $\geq 4$ $(\mathrm{P} \leq 0.05)$. There was no significant difference in the number of calves born in anterior presentation between cows in parities $2-3$ and those in parities $\geq 4 \quad(\mathrm{P}>0.05)$. Also, significantly more dystocia cases were encountered in first-calf heifers compared with those occurred in cows in parities $2-3$ or $\geq 4(\mathrm{P} \leq 0.05)$ but there was no significant difference in this regard between the cows in parities 2-3 and those in parities $\geq 4(\mathrm{P}>0.05)$. In addition, the results revealed that DYS due to FPD mostly affected the primiparous cows and that the multiparous cows were mostly affected by dystocia due to TB, UI and UT. Also, the results showed that significantly most DYS cases occurred during winter compared with spring, summer or autumn $(\mathrm{P} \leq 0.05)$, of which the majority was due to FPD. On the other hand, the least DYS cases were observed in summer months, of which the majority was again due to FPD. Finally, there was no significant difference in the overall incidence of dystocia between spring, summer and autumn $(\mathrm{P}>0.05)$.

\section{REFERENCES}

Berger, P. J., A. C. Cubas, K. J. Koehler \& M. H. Healey, 1992. Factors affecting dystocia and early calf mortality in Angus cows and heifers. Journal of Animal Science, 70, 1775-1786.

Berry, D. P., J. M. Lee, K. A. Macdonald \& J. R. Roche, 2007. Body condition score and body weight effects on dystocia and stillbirths and consequent effects on postcalving performance. Journal of Dairy Science, 90, 4201-4211.

Dematawewa, C. M. B. \& P. J. Berger, 1997. Effect of dystocia on yield, fertility, and cow losses and an economic evaluation of dystocia scores for Holsteins. Journal of Dairy Science, 80, 754-761.

Ghanem, M. E., H. Higuchi, E. Tezuka, H. Ito, B. Devkota, Y. Izaike \& T. Osawa, 2013. Mycoplasma infection in the uterus of early postpartum dairy cows and its relation to dystocia and endometritis. Theriogenology, 79, 180-185.

Holland, M. D., N. C. Speer, D. G. LeFever, R. E. Taylor, T. G. Field \& K. G. Odde, 1993. Factors contributing to dystocia due to fetal malpresentation in beef cattle. Theriogenology, 39, 899-908.

Lombard, J. E., F. B. Garry, S. M. Tomlinson \& L. P. Garber, 2007. Impacts of dystocia on health and survival of dairy calves. Journal of Dairy Science, 90, 1751-1760.

Majeed, A. F., J. B. Ali \& M. B. Taha, 1989. A preliminary study on dystocia in local breed Iraqi cattle. Preventive Veterinary Medicine, 7, 219-223.

Manfredi, E., V. Ducrocq \& J. L. Foulley, 1991. Genetic analysis of dystocia in dairy cattle. Journal of Dairy Science, 74, 17151723.

Mee, J. F., 2004. Managing the dairy cow at calving time. Veterinary Clinic of North American Food Animal Practice, 20, 521546.

Mee, J. F., 2008. Prevalence and risk factors for DYS in dairy cattle: A review. The Veterinary Journal, 176, 93-101.

Mee, J. F., D. P. Berry \& A. R. Cromie, 2011. Risk factors for calving assistance and dystocia in pasture-based Holstein-Friesian heifers and cows in Ireland. The Veterinary Journal, 187, 189-194.

Meijering, A., 1984. Dystocia and stillbirth in cattle - A review of causes, relations and 
Incidence of different types of dystocia in different seasons of the year and parities in Iranian ....

implications. Livestock Production Science, 11, 143-177.

Meyer, C. L., P. J. Berger, K. J. Koehler, J. R. Thompson \& C. G. Sattler, 2001. Phenotypic trends in incidence of stillbirth for Holsteins in the United States. Journal of Dairy Science, 84, 515-523.

Micke, G. C., T. M. Sullivan, P. J. Rolls, B. Hasell, R. M. Greer, S. T. Norman \& V. E. A. Perry, 2010. Dystocia in 3-year-old beef heifers; Relationship to maternal nutrient intake during early- and midgestation, pelvic area and hormonal indicators of placental function. Animal Reproduction Science, 118, 163-170.

Nix, J. M., J. C. Spitzer, L. W. Grimes, G. L. Burns \& B. B. Plyler, 1998. A retrospective analysis of factors contributing to calf mortality and dystocia in beef cattle. Theriogenology, 49, 1515-1523.

Noakes, D. E., T. J. Parkinson \& G. C. W. England, 2009. Veterinary Reproduction and Obstetrics, $9^{\text {th }}$ edn, Saunders, Elsevier, London, p. 212

Norman, H. D., J. L. Hutchison \& Miller, 2010. Use of sexed semen and its effect on conception rate, calf sex, dystocia, and stillbirth of Holsteins in the United States. Journal of Dairy Science, 93, 3880-3890.

Olson, K. M., B. G. Cassell, A. J. McAllister \& S. P. Washburn, 2009. Dystocia, stillbirth, gestation length, and birth weight in Holstein, Jersey, and reciprocal crosses from a planned experiment. Journal of Dairy Science, 92, 6167-6175.

Osinga, A., 1978. Endocrine aspects of bovine dystocia with special reference to estrogens. Theriogenology, 10, 149-166.

Proudfoot, K. L., J. M. Huzzey \& M. A. G. von Keyserlingk, 2009. The effect of dystocia on the dry matter intake and behavior of Holstein cows. Journal of Dairy Science, 92, 4937-4944.
Sasaki, Y., M. Uematsu, G. Kitahara, T. Osawa \& M. Sueyoshi, 2014. Effects of stillbirth and dystocia on subsequent reproductive performance in Japanese Black cattle. The Veterinary Journal, 200, 462463.

Schuenemann, G. M., I. Nieto, S. Bas, K. N. Galvão \& J. Workman, 2011. Assessment of calving progress and reference times for obstetric intervention during dystocia in Holstein dairy cows. Journal of Dairy Science, 94, 5494-5501.

Steinbock, L., A. Näsholm, B. Berglund, K. Johansson \& J. Philipsson, 2003. Genetic effects of stillbirth and calving difficulty in Swedish Holsteins at first and second calving. Journal of Dairy Science, 86, 2228 2235.

Paper received 06.12.2016; accepted for publication 06.02.2017

\section{Correspondence:}

M. Goli, DVM, DVSc

Department of Clinical Science, Faculty of Veterinary Medicine, Razi University, P.O. Box: 6715685414, Kermanshah, Iran tel: +988338329540 , fax: +988338320041 mobile: +989143418361 e-mail: mojtabagoli@yahoo.com; mojtabagoli@razi.ac.ir; 